\title{
Novel Modulator Topology for Corona Plasma Generation
}

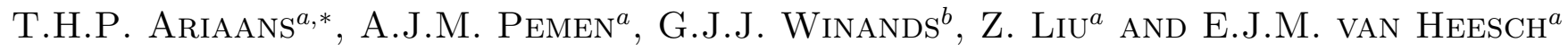 \\ ${ }^{a}$ Eindhoven University of Technology, P.O. Box 513, 5600 MB, Eindhoven, The Netherlands
}

${ }^{b}$ HMVT, Ede, The Netherlands

\begin{abstract}
Gas cleaning using plasma technology is slowly introduced into industry nowadays. Several challenges still have to be overcome: increasing the scale, safety, life-time and reducing costs. In 2006 we demonstrated a $20 \mathrm{~kW}$ nanosecond pulsed corona system. The electrical efficiency was $>90 \%$. O-radical yields were found to be very high $(3-7 \mathrm{~mole} / \mathrm{kWh})$. However, to be competitive, high costs of the pulsed power technology are still a major hurdle. Here we present a novel modulator for efficient generation of large volume corona plasma. Only a small amount of expensive high-voltage components are required. Switching is done at an intermediate voltage level of $1 \mathrm{kV}$ with standard thyristors. At the high-voltage side, only a diode and a pulse transformer are needed. The estimated costs are about $5 \mathrm{kEuro} / \mathrm{kW}$, whereas for state-of-the-art pulsed power technology these costs usually are about 20-30 kEuro/kW. Detailed investigations on the modulator and a wire-plate corona reactor will be presented. Modulator parameters have been varied systematically as well as reactor parameters (number of electrodes, electrode-plate distance). The O-radical yield was determined from the measured ozone concentrations at the exhaust of the reactor. With a detailed kinetic model, ozone concentrations could be calculated back to the initial $\mathrm{O}^{*}$-yields. The following conclusions will be discussed: for all parameters, an electrical efficiency of $>90 \%$ could be obtained. With fast imaging, the average streamer width was found to be $\sim 737 \mu \mathrm{m}$ and an estimate for the plasma volume was made. The obtained yields of O-radicals $(1-4 \mathrm{~mole} / \mathrm{kWh})$ are excellent. The conditions to obtain high yields will be discussed.
\end{abstract}

PACS numbers: 52.50.Dg, 52.70.Ds, 52.70.Kz, 52.80.Hc, 82.33.Xj, 96.60.pf

\section{Introduction}

Using pulsed power systems as a technology for pollution emission control is a promising application. Although there are several ways to generate streamers, the focus here is on AC/DC-pulsed power induced plasma.

The principle of an AC/DC-pulsed system is based on electrical discharges created by high voltage pulses. One of the possible appearances of electrical discharges is corona plasma. Under the right conditions, this plasma can create new electrons and ions, and also radicals. The radicals enable several chemical conversion reactions: decrease molecular mass of hydrocarbons (tar-cracking) [1], convert odour into non-smelling compounds (odour-removal) [2], killing micro organisms in food (pasteurisation). Other applications, like surface activation of textiles or biogas conditioning, are investigated and will be available in the future.

To demonstrate the feasibility of the AC/DC-pulsed technology, a demonstration is designed. The system has a typical output power of $10 \mathrm{~kW}$.

\section{Experimental setup}

In order to investigate all the characteristics (electrical, chemical and optical) of AC/DC-pulsed corona, the

* corresponding author; e-mail: t.h.p.ariaans@tue.nl following power modulator was used (see Fig. 1a). The pulsed power modulator produces high voltage pulses according the principle of resonant charging [3]. First, the low voltage capacitance $\left(C_{\mathrm{L}}\right)$ is charged to $1 \mathrm{kV}\left(\mathrm{V}_{\mathrm{Cl}+}\right)$ and then discharged $\left(\mathrm{V}_{\mathrm{Cl}-}\right)$. As a result the corona reactor is charged (via TR) to a peak voltage $\left(V_{\mathrm{P}}\right)$. The reactor discharges as result of the corona plasma to a lower voltage $\left(V_{\mathrm{DC}}\right)$ (see Fig. $\left.1 \mathrm{~b}\right)$. The following equations were derived for the calculation of the energy delivered by $C_{\mathrm{L}}\left(E_{\mathrm{Cl}}\right)$ and the corona energy $\left(E_{\mathrm{t}}\right)$, consisting of the energy dissipated during charging $\left(E_{\mathrm{P}}\right)$ and the discharging energy $\left(E_{\mathrm{H}}\right)$ :

$$
\begin{aligned}
E_{\mathrm{Cl}} & =(1 / 2) C_{\mathrm{L}}\left(V_{\mathrm{Cl}+}^{2}-V_{\mathrm{Cl}-}^{2}\right), \\
E_{\mathrm{P}} & =\int_{0}^{t\left(V=V_{\mathrm{P}}\right)} V I_{\mathrm{r}} \mathrm{d} t-(1 / 2) C_{\mathrm{r}}\left(V_{P}^{2}-V_{\mathrm{DC}}^{2}\right), \\
E_{\mathrm{H}} & =(1 / 2) C_{\mathrm{h}}\left(V_{\mathrm{P}}^{2}-V_{\mathrm{DC}}^{2}\right), \\
E_{\mathrm{t}} & =\int_{0}^{t\left(V=V_{\mathrm{P}}\right)} V I_{\mathrm{r}} \mathrm{d} t+(1 / 2)\left(C_{h}-C_{r}\right) \\
& \times\left(V_{\mathrm{P}}^{2}-V_{\mathrm{DC}}^{2}\right),
\end{aligned}
$$

where $V$ is the reactor voltage, $I_{\mathrm{r}}$ is the reactor current and $C_{\mathrm{h}}$ and $C_{\mathrm{r}}$ are the high voltage and reactor capacitance, respectively.

For the chemical measurements, the concentration of ozone in the exhaust of the reactor can be used to measure the O-radical concentration produced by the plasma. 

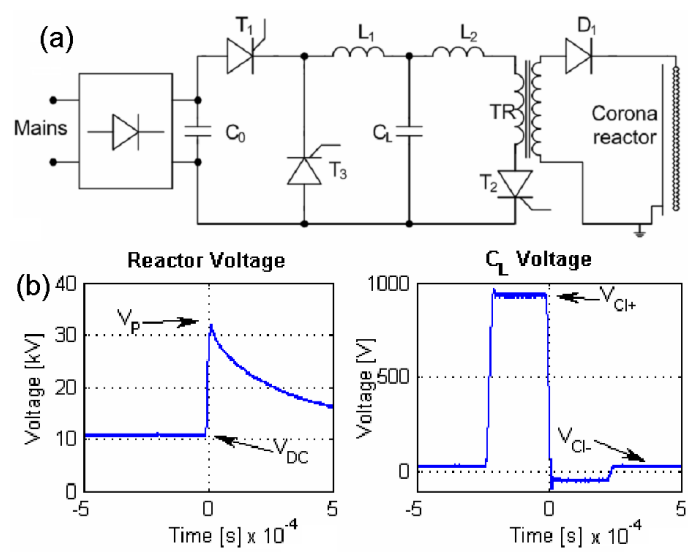

Fig. 1. (a) AC/DC-pulsed power modulator. (b) Voltage waveforms of the reactor voltage (left) and the low voltage capacitor (right).

The ozone concentration was determined using a UV absorption technique. The developed kinetic model was based on the chemical reactions that occur in the reactor [4]. The remaining unknown parameter is the plasma volume. By means of optical measurements (i.e. ICCD-camera), this volume was determined.

\section{Results and discussion}

During the experiments the first thing that became evident is that plasma needs sufficient room to dissipate the available energy. With $C_{\mathrm{L}}=3 \mu \mathrm{F}$ and a reactor configuration of 1,2 and 4 channels $\left(C_{\mathrm{r}} \sim 0.25 \mathrm{nF} /\right.$ channel $)$, the experiments could be performed without problems. However, with $C_{\mathrm{L}}=6 \mu \mathrm{F}$, many electrical breakdowns were observed. The most important parameter for the experiments was $C_{\mathrm{h}}$.

The reactor voltage is affected by $C_{\mathrm{h}}$ (see Fig. 2a). A low value of $C_{\mathrm{h}}$ results in a high peak voltage and a low DC voltage. A higher value of $C_{\mathrm{h}}$ means that the reactor is charged and discharged slower. During slower charging, the voltage is not able to overshoot the plasma inception voltage as far as with a low $C_{\mathrm{h}}$ value, which results in a lower peak voltage. The number of reactor channels has an effect on the DC voltage as well. This can be explained by the fact that more channels imply more plasma and as a result, a lower plasma resistance. The reactor discharges faster. The energy ratio $\left(E_{\mathrm{P}} / E_{\mathrm{t}}\right)$ is negatively affected by $C_{\mathrm{h}}$ (see Fig. 2b). A higher $C_{\mathrm{h}}$ implies that less energy is dissipated during charging of the reactor. On the other hand, the energy transfer efficiency $\left(E_{\mathrm{h}} / E_{\mathrm{Cl}}\right)$ improves for increasing $C_{\mathrm{h}}$ (see Fig. 2c). The overall efficiency is high: around $92 \% \pm 6 \%$.

In order to estimate the plasma volume several photographs were taken under different circumstances. The plasma depends on the applied voltage and thus on the electric field in the reactor gap. If the applied voltage is high (i.e. $V_{\mathrm{P}}=31.9 \mathrm{kV}$ and $V_{\mathrm{DC}}=20.3 \mathrm{kV}$ )

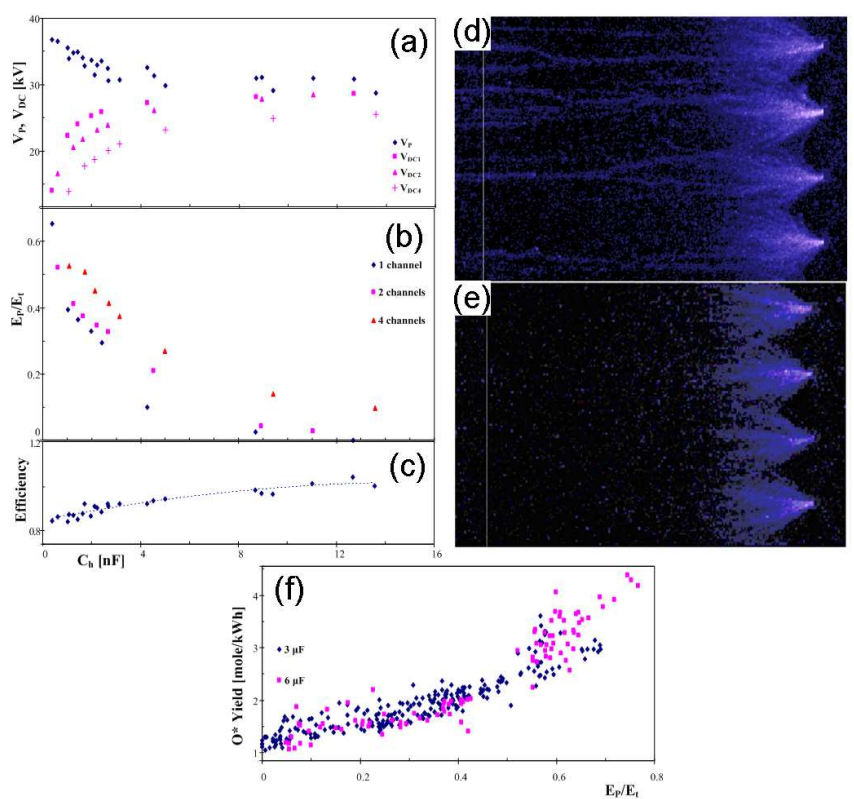

Fig. 2. (A) Reactor voltage. (B) Energy ratio $\left(E_{\mathrm{P}} / E_{\mathrm{t}}\right) .(\mathrm{C})$ Energy transfer efficiency. (D) Plasma appearance with $V_{\mathrm{p}}=31.9 \mathrm{kV}$ and $V_{\mathrm{DC}}=20.3 \mathrm{kV}$. (E) Plasma appearance with $V_{\mathrm{p}}=23.8 \mathrm{kV}$ and $V_{\mathrm{DC}}=$ $19.5 \mathrm{kV}$. (F) O-radical yield.

streamers cross the complete gap (see Fig. 2d). However, if the applied voltage is low (i.e. $V_{\mathrm{P}}=23.8 \mathrm{kV}$ and $V_{\mathrm{DC}}=19.5 \mathrm{kV}$ ), streamers are only visible in the vicinity of the electrode (see Fig. 2e). Apparently, the electric field is lower than the critical field strength of $5-8 \mathrm{kV} / \mathrm{cm}$ which is required for streamers to propagate [2]. From the photographs with crossing streamers the average streamer width was determined to be $737 \mu \mathrm{m}$ and the plasma volume was estimated to be $\sim 0.5-2.0 \mathrm{dm}^{3} /$ channel. A sensitivity check has shown that the maximum difference in $\mathrm{O}^{*}$ yield as a result of this estimate is acceptable: $12 \%$.

The O-radical yield depends on $E_{\mathrm{P}} / E_{\mathrm{t}}$ and is controllable between 1-4 mole/kWh (see Fig. 2f), which is comparable to ns-pulsed plasma $(3-7$ mole $/ \mathrm{kWh})$. The higher the $E_{\mathrm{P}} / E_{\mathrm{t}}$, the higher the $\mathrm{O}^{*}$ yield. This implies that oxygen radicals are created more efficiently when the energy is dissipated during the charging stage of the reactor. In order to achieve high yields, $C_{\mathrm{h}}$ needs to be low. This implies with a high $V_{\mathrm{P}}$ and a low $V_{\mathrm{DC}}$ (inclined towards pulsed plasmas).

\section{Conclusions}

It can be concluded that AC/DC-pulsed plasma is a good alternative for the ns-pulsed plasma. The efficiency of the new system is high $(>90 \%)$. With optical measurements the streamer width was determined to be $737 \mu \mathrm{m}$ and an estimation was made for the plasma volume. The chemical yield of this system is $1-4 \mathrm{~mole} / \mathrm{kWh}$, which is comparable with ns-pulsed plasma. 


\section{Acknowledgments}

The work is supported by the Dutch Innovative Research Program IOP.

\section{References}

[1] S.A. Nair, A.J.M. Pemen, K. Yan, F.M. van Gompel, H.E.M. van Leuken, E.J.M. van Heesch, K.J. Ptasinski, A.A.H. Drinkenburg, Plasma Chem. Plasma Proc. 23, 665 (2003).
[2] G.J.J. Winands, K. Yan, A.J.M. Pemen, S.A. Nair, Z. Liu, E.J.M. van Heesch, IEEE Trans. Plasma Sci. 34, 2426 (2006).

[3] K. Yan, E.J.M. van Heesch, A.J.M. Pemen, P.A.H.J. Huijbrechts, P.C.T. van der Laan, Rev. Sci. Instrum. 72, 2443 (2001).

[4] R. Peyrous, Ozone Sci. Eng. 12, 41 (1990). 